\title{
Multiple partnerships and risk for HIV among the Garífuna minority population in Belize
}

\author{
Justin Buszin ${ }^{1 *}$, Benjamin Nieto-Andrade ${ }^{2}$, Jorge Rivas $^{2}$, Kim Longfield $^{1}$ \\ ${ }^{1}$ Research and Metrics Department, Population Services International, Washington DC, USA; \\ *Corresponding Author: justin.buszin@gmail.com \\ ${ }^{2}$ Pan American Social Marketing Organization, Guatemala City, Guatemala
}

Received 27 May 2012; revised 25 June 2012; accepted 1 July 2012

\begin{abstract}
Belize has the highest rates of HIV infection in Central America and is experiencing a generalized epidemic. The Garífuna, a minority ethnic population, is at risk for HIV. This study uses survey data from Garífuna men and women to examine the frequency of multiple partnerships as well as sociodemographic characteristics and behavioral constructs correlated with having multiple partners. A high proportion of respondents reported having multiple partners, but rates were significantly higher for men, and men had a higher mean number of partners than women. A high proportion of respondents reported having a sexually transmitted infection (STI) in the last year, with more men reporting a history of STIs than women. Regression results show the importance of improving men and women's perceived susceptibility for HIV and encouraging them to know their HIV status. Reinforcing a social norm for partner reduction would also benefit men. Study findings support the need for HIV counseling and testing in Garífuna communities as well as STI prevention, diagnosis and treatment. This study demonstrates that reducing multiple partnerships among Garífuna men and women is critical for reducing the spread of HIV in Belize.
\end{abstract}

Keywords: Garífuna; Belize; Multiple Partnerships; HIV; STI

\section{INTRODUCTION}

Belize's 2.4\% HIV infection rate is the highest in Central America [1]. By UNAIDS and World Health Organization standards, this is a generalized epidemic, one in which HIV prevalence exceeds $1 \%$ among the general adult population. The epidemic in Belize thus follows a pattern of transmission more common in Africa and the Caribbean than in other parts of Central America, where the rate of infection among the general population ranges from $0.2 \%$ in Nicaragua to $0.9 \%$ in Panama [2].

The history of the Garífuna dates back to 1635, when they arrived via slave ships in the Caribbean. They intermarried with local Carib Indians to form the Garífuna population. In 1797, British colonizers relocated many Garifuna to the island of Roatan in Honduras, from where groups migrated to the mainland. They established communities in present-day Honduras, Nicaragua, Guatemala, and Belize [3].

The Garifuna are the fourth-largest ethnic group in Belize, totaling $4.6 \%$ percent of the population [4]. In modern Garífuna society, working-age women often leave to seek jobs in major Central American cities or the United States, typically in the textile industry or as maids, while elder generations care for children [3]. There is also a great deal of out-migration among Garífuna men, who travel to other parts of Belize, neighboring countries, and the United States for work [3]. As a result, many Garífuna households are single-parent (or grandparent) and female-headed [3]. Due to high rates of mobility, Garífuna men and women spend many months apart from one another and may seek casual partners outside of their regular relationships [5-7].

Multiple partnerships are common among Garífuna [3]. Men receive social support to have multiple partners and women are not expected to remain chaste until marriage. Legal marriage occurs in a minority of households and Garifuna women tend to bear children without having a fixed relationship to children's fathers $[3,8]$. While there are no published data on the proportion of Garifuna in Belize who have multiple partnerships, studies from neighboring Honduras suggest that the practice is common. One found that $40 \%$ of Garifuna men reported having sexual encounters with two or more women in the previous six months; $13 \%$ of women reported the same [9]. Another Honduran study revealed that one-third of sexually active Garífuna men reported having more than 
one sexual partner during the previous year while $3 \%$ of Garífuna women reported the same [10].

Studies on HIV prevalence among Garífuna in Belize are limited, though Garífuna in the Central American region are disproportionately affected by HIV. In neighboring Honduras, UNAIDS estimates that $4.5 \%$ of Garífuna are HIV-positive [11]. The spread of HIV through Garífuna communities is likely facilitated by low levels of condom use and high levels of non-monogamous sexual activity [7]. When one or both individuals in a regular sexual partnership maintain other sexual partners simultaneously (i.e., concurrent partners), risk for HIV transmission is increased $[12,13]$. Engaging in multiple or concurrent partnerships has also been associated with the acquisition of STIs, including chlamydia, gonorrhea, and bacterial STIs [14-17]. Simulation studies have demonstrated that HIV/STI-positive persons who have concurrent partnerships are at risk of transmitting infection to different partners at the same time, and suggest that even small reductions in levels of partner concurrency may have a dramatic impact on HIV/STI transmission through sexual networks in some populations [13].

This study used data from a survey conducted among Garífuna men and women in Belize to examine the frequency of multiple partnerships. We also examined sociodemographic characteristics and behavioral constructs correlated with having multiple partnerships.

\section{PSI and PASMO Activities Targeting Garífuna in Belize}

Population Services International (PSI) has operated in
Belize since 1999, first through the Pan-American Social Marketing Organization (PASMO) and now as part of PSI's regional efforts in the Caribbean. PSI implements a program for Garífuna in the Cayo, Stann Creek, and Toledo regions, which account for approximately $71 \%$ of the Garífuna population in Belize [4].

The purpose of the program is to promote safer sexual behavior among Garífuna men and women and increase their opportunity, ability and motivation to adopt key protective behaviors. Current strategies include highcoverage social marketing of condoms, interpersonal communication (IPC) facilitated by Garífuna educators, mass media, and outreach. Expanded strategies will include messages to decrease discriminatory attitudes based on sexual orientation and HIV status; improving access to a package of essential preventative health services; and increasing the involvement of private health providers by expanding their services in Garífuna communities.

\section{METHODS}

\subsection{Theoretical Framework}

PSI's internal framework for behavior change and health impact guided this study: the Performance Framework for Social Marketing (PERForM) and the PSI Behavior Change Framework (Figure 1).

The PERForM framework summarizes known determinants of behavior and the relationship between behavior and health. It describes a set of theoretical pathways that social marketing strategies use to improve healthrelated behaviors by influencing behavioral constructs

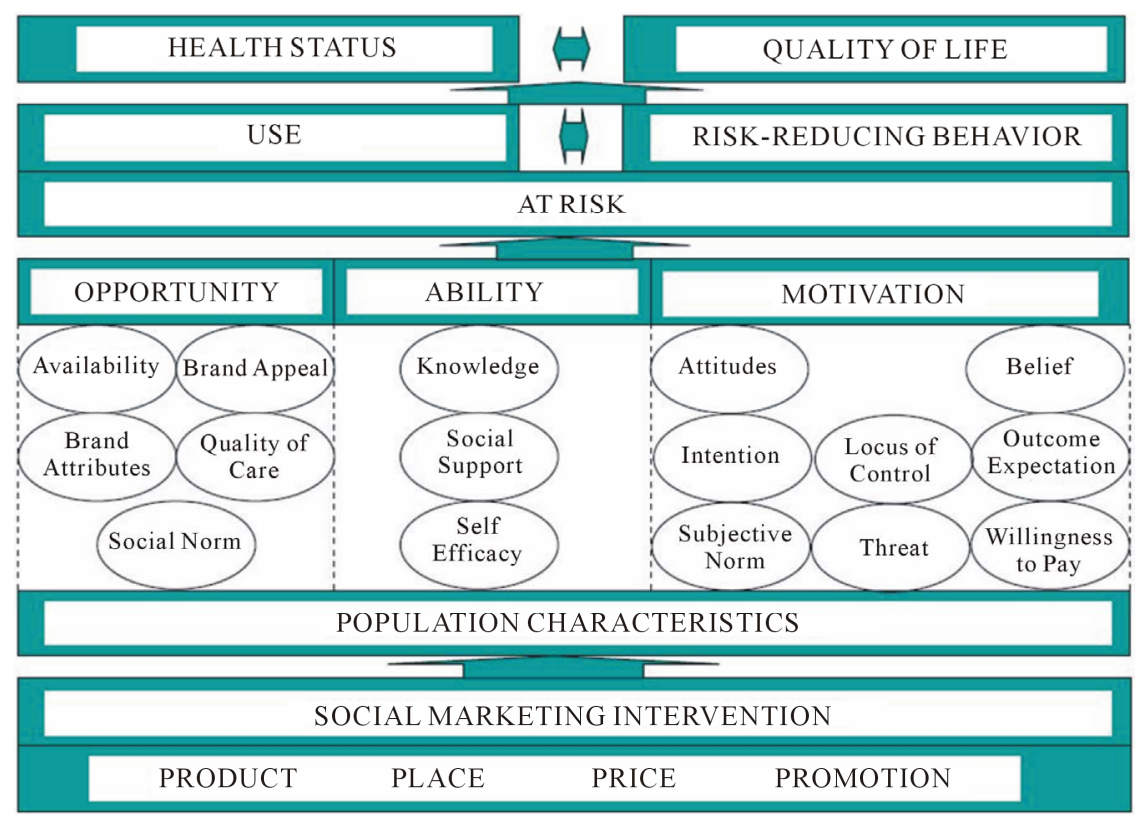

Figure 1. The behavior change framework. 
that increase the use of protective products or services or reduce risk behavior; in this case, having multiple partners. The second level of the PERForM framework contains categories of constructs from the PSI Behavior Change Framework that are organized by opportunity, availability and motivation as originally introduced by Rothschild [18]. Constructs come from health behavior theories including the Health Belief Model [19] and the Theory of Reasoned Action [20], as well as marketing theory [21].

\subsection{Sample and Design}

The study population was Garífuna men and women aged 18 - 50 residing in urban Cayo, Stann Creek, and Toledo, Belize. Data were collected in 2007 and originally used to identify factors correlated with condoms use among occasional partners.

We used a multi-stage cluster sampling approach with clusters defined as neighborhoods. The number of Garífuna living in each neighborhood determined the cluster size. We used probability-proportional-to-size sampling to select clusters and then randomly sample a fixed number of Garífuna households from each cluster. Within each household, we randomly chose an individual from among all household residents who met the eligibility criteria: sexually active aged 15 to 49 residing in Cayo, Stann Creek or Toledo.

Interviewers obtained oral consent from respondents and administered study questionnaires using personal digital assistants (PDAs). When respondents were uncomfortable giving responses to the interviewer, they were allowed to use the PDA to input their own responses. Once entered into PDAs, interviewers could not match data to individuals interviewed during that day. The PSI Research Ethics Board reviewed and approved the secondary data analysis plan used for this study. We used a total of 530 records for this study.

\subsection{Measures}

The questionnaire contained several modules. For this study, we used: sociodemographic characteristics, history of STIs, sexual behavior, and behavioral constructs thought to be related to multiple partnerships. Sociodemographic characteristics included age, sex, educational level, and marital status. The behavior of interest was the number of regular, occasional and commercial partners in the past 30 days. A "regular partner" was defined as a partner with whom a respondent had sex on a habitual basis and had been together for at least three months (including marital partners). "Occasional" partners were seen less often and included anyone with whom a respondent had a sexual encounter, but had no intention of seeing again. "Occasional partners" had been together for less than 3 months or had no emotional commitment to the respondent. "Commercial partners" were any partners who the respondent paid for sex. We ensured that there was no double-counting of partners in the last 30 days by placing partners in only one category: regular, occasional, or commercial. By knowing the number of each type of partner a respondent had in the past 30 days, and his/her marital status, we were able to determine the total number of partners in the last 30 days. We used a continuous variable to measure the behavior of interest, number of sexual partners in the last 30 days.

\subsection{Analysis}

SPSS 17.0 was used for all data entry and analyses. We conducted reliability analyses on scaled items used to measure behavioral constructs and kept those where groups of items achieved a Chronbach's alpha of 0.70 or higher. This was the case for social norms and threat (susceptibility to HIV). Items that did not reliably factor with at least two other items were analyzed separately, which was the case for outcome expectations, beliefs, attitudes and intentions. Some scaled items were presented as negative statements in the questionnaire; in such cases, the items were reverse-coded prior to analysis. All scaled items were measured on a four-point scale. Results of the reliability analysis are contained in Table 1. For knowledge items, we created an index by tallying five dichotomous questions (right/wrong) to obtain an overall knowledge score that ranges from one to five.

We used Poisson regression models to identify factors correlated with the number of reported partners in the past 30 days. Results for men and women were modeled separately via two incremental models. The first contained only sociodemographic characteristics. The second included sociodemographic characteristics, STI history, and behavioral constructs.

\section{RESULTS}

Table 2 presents descriptive statistics for men and women, with significant differences noted. The distribution of men and women across cities was uneven. Significantly more men than women participated in the study in Cayo and Toledo $(17.9 \%$ vs $3.0, \mathrm{p}<0.001$; and $39.9 \%$ vs $23.9 \%$, p $<0.001$, respectively) while more women participated in Stann Creek (73.1\% vs 42.2\%, p < $0.001)$. There were no significant differences in marital status or educational levels between men and women.

A high proportion of men and women reported having more than one sexual partner in the last 30 days, but rates were significantly higher for men $(58.7 \%$ vs $32.9 \%$, p < $0.001)$. The mean number of partners for men was also significantly higher than the mean number for women (4.4 vs 2.3, p < 0.001). Men and women reported having 
Table 1. Descriptive statistics of garifuna men and women in Cayo, Toledo, and Stann Creek, Belize, 2008.

\begin{tabular}{|c|c|}
\hline Dependent and Demographic Independent Variables & $\mathbf{N}=\mathbf{5 3 1}$ \\
\hline Had more than 1 partner in last 30 days & $50.4 \%$ \\
\hline \multicolumn{2}{|l|}{ Age } \\
\hline $15-25$ & $53.5 \%$ \\
\hline $26-50$ & $46.5 \%$ \\
\hline \multicolumn{2}{|l|}{ Education } \\
\hline Primary school or less & $27.7 \%$ \\
\hline Completed secondary school or more & $72.3 \%$ \\
\hline Married & $37.9 \%$ \\
\hline Has at least 1 child & $47.0 \%$ \\
\hline Male & $68.5 \%$ \\
\hline \multicolumn{2}{|l|}{ City } \\
\hline Cayo & $13.2 \%$ \\
\hline Toledo & $34.9 \%$ \\
\hline Stann Creek & $51.9 \%$ \\
\hline Had STI in the last year & $40.6 \%$ \\
\hline \multicolumn{2}{|l|}{ Opportunity, Ability, Motivation Variables } \\
\hline Knowledge index & 4.11 \\
\hline Social norms supporting partner reduction scale mean & 2.79 \\
\hline Reducing one's number of occasional partners reduces the risk of HIV transmission & 3.11 \\
\hline Reducing one's number of regular partners reduces the risk of HIV transmission & 3.05 \\
\hline Having several different partners at the same time is exciting & 2.61 \\
\hline It is important to know your HIV status & 3.42 \\
\hline I plan to get tested for HIV in the next 3 months & 2.41 \\
\hline I feel at risk of acquiring AIDS & 1.76 \\
\hline It is necessary to seek medical treatment for STIs & 2.97 \\
\hline
\end{tabular}

All means reported on a scale of 1 - 4, except Knowledge which is $1-5$.

more occasional partners than other types of partners, and men reported significantly more occasional (2.66 vs $1.22, \mathrm{p}<0.01)$ and commercial partners $(0.97$ vs 0.29 , $\mathrm{p}$ $<0.01)$ than women. A high proportion of men and women reported having an STI in the last year, but more men reported having STIs than women $(48.2 \%$ vs $24.0 \%$, $\mathrm{p}<0.01$ ).

Men and women differed significantly on six of the eight behavioral constructs. Women scored higher on the social norms scale supporting partner reduction $(2.87 \mathrm{vs}$ $2.76, \mathrm{p}<0.05$ ). Women were also more likely than men to disagree with the following statements "having several different partners at the same time is exciting" (3.05 vs $2.41, \mathrm{p}<0.001)$ and "having several different partners at the same time is fun" ( 3.05 vs $2.47, \mathrm{p}<0.001)$. Men, on the other hand, were more likely than women to state that "it is important to know one's HIV status" (3.46 vs 3.32, $\mathrm{p}<0.05$ ) and that they intend to get tested for HIV in the next three months (3.06 vs $2.83, \mathrm{p}<0.01)$. Women also had a higher perceived threat susceptibility to HIV (2.15 vs $1.90, \mathrm{p}<0.001)$. There were no significant differences between men and women on the knowledge index or outcome expectations.

Table 3 presents the results of the Poisson regression models for men. The first model presents sociodemographic characteristics correlated with the reported number of partners in the last 30 days while the second model included STI history and behavioral constructs. Seven 
Table 2. Descriptive statistics by gender.

\begin{tabular}{|c|c|c|c|}
\hline Dependent and Demographic Independent Variables & Men & Women & Sig \\
\hline \multicolumn{4}{|l|}{ Education } \\
\hline Primary school or less & $25.4 \%$ & $32.9 \%$ & \\
\hline Completed secondary school or more & $74.6 \%$ & $67.1 \%$ & \\
\hline Married & $35.3 \%$ & $43.7 \%$ & \\
\hline \multicolumn{4}{|l|}{ City } \\
\hline Cayo & $17.9 \%$ & $3.0 \%$ & *** \\
\hline Toledo & $39.9 \%$ & $23.9 \%$ & *** \\
\hline Stann Creek & $42.2 \%$ & $73.1 \%$ & *** \\
\hline Had more than 1 partner in the last 30 days & $58.7 \%$ & $32.9 \%$ & *** \\
\hline Had STI in the past year & $48.2 \%$ & $24.0 \%$ & *** \\
\hline Indices and Scale Independent Variables & $\mu$ & $\mu$ & \\
\hline Knowledge index & 4.16 & 4.01 & \\
\hline Social norms supporting partner reduction scale & 2.76 & 2.87 & * \\
\hline Reducing one's number of occasional partners reduces the risk of HIV transmission & 3.12 & 3.07 & \\
\hline Reducing one's number of regular partners reduces the risk of HIV transmission & 3.08 & 2.99 & \\
\hline Having several different partners at the same time is not exciting & 2.41 & 3.05 & *** \\
\hline Having several different partners at the same time is not fun & 2.47 & 3.05 & *** \\
\hline It is important to know your HIV status & 3.46 & 3.32 & ${ }^{*}$ \\
\hline I plan to get tested for HIV in the next 3 months & 3.06 & 2.83 & ** \\
\hline \multicolumn{4}{|l|}{ Number of Partners Data } \\
\hline Mean number of partners in the past 30 days & 4.4 & 2.3 & *** \\
\hline Mean number of regular partners in the past 30 days & 0.82 & 0.82 & \\
\hline Mean number of occasional partners in the past 30 days & 2.66 & 1.22 & ** \\
\hline Mean number of commercial partners in the past 30 days & 0.97 & 0.29 & $* *$ \\
\hline
\end{tabular}

${ }^{*} \mathrm{p}<0.05,{ }^{* *} \mathrm{p}<0.01,{ }^{* * *} \mathrm{p}<0.001$; All means reported on a scale of $1-4$, except Knowledge which is $1-5$.

factors were significantly correlated with having fewer multiple partners in the last 30 days: being married $(p<$ $0.001)$, having a higher level of education $(\mathrm{p}<0.001)$, living in Stann Creek $(p<0.001)$, showing support for the social norm of partner reduction $(\mathrm{p}<0.05)$, believing that one is at increased risk for HIV ( $p<0.001)$, believing that reducing one's number of occasional partners reduces one's risk of HIV ( $p<0.001)$, and disagreeing with the statement "having several different partners at the same time is exciting" $(p<0.001)$. Two factors were associated with having a higher number of partners in the last 30 days: having an STI in the last year $(\mathrm{p}<0.001)$ and agreeing that "it is important to know your HIV status" ( $p<0.01)$. The model for men explains $31 \%$ of the variability in having multiple partners.
Table 4 presents the results of the Poisson regression models for women. The sociodemographic characteristics that were significant in the first model were not significant in the second model when STI history and behavioral constructs are added. Likewise, fewer behavioral constructs were significant in the model for women than for men. One factor was significantly correlated with having fewer multiple partners in the last 30 days: believing that one is at increased risk for HIV $(p<0.001)$. Three factors were associated with having a higher number of partners in the last 30 days: having an STI in the last year ( $p<0.001)$, agreeing that "it is important to know your HIV status" $(\mathrm{p}<0.05)$, and intending to get tested for HIV in the next three months $(p<0.01)$. The model for women explains $42 \%$ of the variability in 
Table 3. Poisson regression results predicting multiple partners among Male Garifuna in last 30 days.

\begin{tabular}{|c|c|c|c|}
\hline \multirow{2}{*}{ Independent Variables } & Model 1 & Model 2 & Model 3 \\
\hline & $\beta$ & $\beta$ & $\beta$ \\
\hline Married & $-0.80^{* * *}$ & $-0.69^{* * *}$ & $-0.71^{* * *}$ \\
\hline Age & -0.0001 & -0.003 & -0.005 \\
\hline Education (Index) & $-0.08^{* * *}$ & $-0.10^{* * *}$ & $-0.12^{* * *}$ \\
\hline Cayo (vs Toledo) & $-0.21^{* *}$ & -0.03 & -0.08 \\
\hline Stann Creek (vs Toledo) & $-1.12^{* *}$ & $-0.76^{* * *}$ & $-0.52^{* * *}$ \\
\hline Had STI in the past year & & & $0.37^{* * *}$ \\
\hline Knowledge index & & -0.03 & -0.03 \\
\hline Social norms supporting partner reduction scale & & -0.08 & $-0.09^{*}$ \\
\hline Threat susceptibility to HIV scale & & $-0.39^{* * *}$ & $-0.37^{* * *}$ \\
\hline \multicolumn{4}{|l|}{ Outcome Expectations } \\
\hline Reducing one's number of occasional partners reduces the risk of HIV transmission scale & & $-0.16^{* * *}$ & $-0.14^{* * *}$ \\
\hline Reducing one's number of regular partners reduces the risk of HIV transmission scale & & -0.03 & -0.04 \\
\hline \multicolumn{4}{|l|}{ Beliefs } \\
\hline Having several different sexual partners at the same time is not exciting & & $-0.20^{* * *}$ & $-0.20^{* * *}$ \\
\hline Having several different sexual partners at the same time is not fun & & 0.01 & 0.02 \\
\hline \multicolumn{4}{|l|}{ Attitude } \\
\hline It is important to know your HIV status & & $0.15^{* *}$ & $0.16^{* *}$ \\
\hline \multicolumn{4}{|l|}{ Intention } \\
\hline I plan to get tested for HIV in the next 3 months & & 0.05 & 0.02 \\
\hline Constant & $2.46^{* * *}$ & $3.87^{* * *}$ & $3.69^{* * *}$ \\
\hline Pseudo $\mathrm{R}^{2}$ & 0.20 & 0.30 & 0.31 \\
\hline $\mathrm{N}$ & 363 & 363 & 363 \\
\hline
\end{tabular}

having multiple partners. Also, the correlation between STI history and having more partners was stronger for women than for men. The same is true of the attitude "it is important to know your HIV status".

\section{DISCUSSION}

As with all studies, there were limitations with ours. The focus of the original study was on factors correlated with condom use, not multiple partnerships. While the Poisson models explained a high proportion of the variability in multiple partnerships for men and women, few behavioral constructs were significantly correlated with the outcome of interest in the model for women. The low female sample size $(\mathrm{N}=167)$ may explain a general lack of significant variables. Additional research, especially in-depth, qualitative research would be helpful for un- derstanding more about Garífuna men and women's motivations for seeking and maintaining multiple partners and informing future surveys.

The distribution of men and women across cities was uneven, with more men sampled in Cayo and Toledo, and more women sampled in Stann Creek. We believe this is because Stann Creek, as an urban center, attracts more women relative to Toledo and Cayo, which have agricultural-based economies and historical patterns of seasonal migration among men. During the study, we asked about three different partner types: regular, casual, and commercial partners. The approach we used yielded a proxy for multiple partnerships. In the future, we plan to use a more reliable calendar approach that identifies overlap between partners and allows for estimates of point prevalence for concurrency [13]. 
Table 4. Poisson regression results predicting multiple partners among Female Garifuna in last 30 days.

\begin{tabular}{|c|c|c|c|}
\hline \multirow{2}{*}{ Impendent Variables } & Model 1 & Model 2 & Model 3 \\
\hline & $\beta$ & $\beta$ & $\beta$ \\
\hline Married & $-0.59^{* * *}$ & $-0.33^{*}$ & -0.27 \\
\hline Age & $-0.03^{* * *}$ & -0.01 & -0.02 \\
\hline Education (Index) & -0.02 & -0.02 & -0.03 \\
\hline Cayo (vs Toledo) & $0.51^{* *}$ & 0.14 & 0.07 \\
\hline Stann Creek (vs Toledo) & $-1.26^{* * *}$ & $-0.36^{*}$ & -0.08 \\
\hline Had STI in the past year & & & $0.76^{* * *}$ \\
\hline Knowledge Index & & 0.06 & 0.06 \\
\hline Social norms supporting partner reduction scale & & -0.02 & 0.01 \\
\hline Threat susceptibility to HIV scale & & $-0.50^{* * *}$ & $-0.39^{* * *}$ \\
\hline \multicolumn{4}{|l|}{ Outcome Expectations } \\
\hline Reducing one's number of occasional partners reduces the risk of HIV transmission scale & & -0.02 & -0.04 \\
\hline Reducing one's number of regular partners reduces the risk of HIV transmission scale & & $-0.33^{* * *}$ & -0.21 \\
\hline \multicolumn{4}{|l|}{ Beliefs } \\
\hline Having several different sexual partners at the same time is not exciting & & $-0.47^{* * *}$ & -0.35 \\
\hline Having several different sexual partners at the same time is not fun & & 0.01 & -0.04 \\
\hline \multicolumn{4}{|l|}{ Attitude } \\
\hline It is important to know your HIV status & & $0.33^{* *}$ & $0.33^{*}$ \\
\hline \multicolumn{4}{|l|}{ Intention } \\
\hline I plan to get tested for HIV in the next 3 months & & $0.37^{* * *}$ & $0.24^{* *}$ \\
\hline Constant & $2.59^{* * *}$ & $2.47^{* *}$ & $1.70^{* * *}$ \\
\hline Pseudo $\mathrm{R}^{2}$ & 0.23 & 0.40 & 0.42 \\
\hline $\mathrm{N}$ & 167 & 167 & 167 \\
\hline
\end{tabular}

${ }^{*} \mathrm{p}<0.05,{ }^{* *} \mathrm{p}<0.01,{ }^{* * *} \mathrm{p}<0.001$.

This study adds to the general HIV and public health literature in several ways. To our knowledge, this is the first study among Garífuna men and women in Belize that examines the frequency of multiple partnerships as well as sociodemographic characteristics and behavioral constructs correlated with having multiple partners. We found a high proportion of men and women that reported multiple partnerships; rates were significantly higher for men, and men had a higher mean number of partners. This confirms the suspicion that the spread of HIV through Garífuna communities is facilitated by high levels of non-monogamous sexual activity [7].

After results from the initial study on condom use were disseminated, the PSI program in Belize partnered with a local non-governmental organization (NGO) to work in Garífuna communities and implement programs to promote condom use and participate in voluntarily counseling treatment for STIs. Together, the organizations have developed IPC campaigns and educational materials specifically for Garífuna. The results of this study suggest other appropriate social marketing strategies that can be undertaken.

HIV prevention messages should stress the importance of reducing one's number of sexual partners. Men and women must be convinced that they are susceptible to HIV and understand that it is important to know their HIV status. This study also demonstrated that for men, an intention to get tested for HIV was correlated with a lower number of sexual partners. Taken together, these findings suggest that Garífuna men and women would benefit greatly from having HIV counseling and testing services available in their communities. For men, addi- 
tional messages should increase support for a social norm of partner reduction. Social marketers should also prioritize single men with lower levels of education and those living in Cayo and Toledo with messages.

A high proportion of respondents reported having an STI in the last year, with more men reporting STIs than women. Previous research in Belize supports our findings of high STI rates among the Garífuna [22]. There was also a very strong correlation between STI history and having multiple partners. These results support other literature that has found that having multiple partners facilitates the spread of STIs, including HIV, through sexual networks [23-26]. Future social marketing efforts in Garífuna communities should include STI prevention programs as well as diagnosis and treatment.

This study demonstrates that reducing multiple partnerships among Garífuna men and women is critical for reducing the spread of HIV in Belize. The Garifuna is unique in Central America insofar as the spread of HIV among them is through heterosexual intercourse in any area where transmission is more common among men who have sex with men. Due to the unique nature of the transmission and the Garífuna's afro-Caribbean roots, programs that seek to reduce HIV transmission need to tailor their prevention messages differently for Garífuna than they would for other groups in Belize. Specifically, a program that focuses messages on risk perception that clearly communicates the relationship between having STIs and number of partners should be implemented in the first stage. Second, messages need to focus on singlepartner relationships and commitments, and men with multiple partners should not view themselves with personal pride and prestige (i.e. quality of relationships over quantity). Third, this may be out of the hands of the program, improving gender equality among this population could also reduce the number of partners both men and women have. In Caribbean populations, it is not uncommon to exchange material goods or provide gifts in exchange for sex. This may be due to the lack of sufficient personal funds to buy such material goods. By providing women with education and improving gender equality, women's access to material goods will improve so they do not need to be in a relationship with a man in order to get material goods to survive. We believe this three-stage approach is supported by the findings, and PSI Belize has begun implemented the first stage.

\section{ACKNOWLEDGEMENTS}

The authors wish to thanks the donors, KfW, CARICOM and Options for their funding support for this report. We also want to acknowledge CID Gallup for their collection of data and fieldwork, as well as data processing. We thank Abigail Harrison for her helpful comments on this paper, which was presented at the Population Asso- ciation of America Annual Conference in April 2009. We also thank Julia Roberts, Country Representative for the Caribbean region, and Lara Smith, Country Representative for Belize, for reviewing this report and for providing details about the program. Nadja Vielot greatly aided with the literature review.

\section{REFERENCES}

[1] UNGASS (2010) UNGASS country progress report: Belize.

http://www.unaids.org/en/dataanalysis/monitoringcountry progress/2010progressreportssubmprogressreportss/belize 2010 country progress report en.pdf

[2] WHO (2011) Global health observatory data repository. http://apps.who.int/ghodata/

[3] Matthei, L.M. and Smith, D.A. (2008) Flexible ethnic identity, adaptation, survival, resistance: The Garífuna in the world system. Social Identities, 14, 215-232. doi:10.1080/13504630801933290

[4] Statistical Institute of Belize (2011) Main results of 2010 population and housing census.

http://www.statisticsbelize.org.bz/dms20uc/dynamicdata/ docs/20110505004542 2.pdf

[5] Kishamwe, C., Vissers, D., Urassa M., Isingo, R., Mwaluko, G., Borsboom, G., Voeten, H., Zaba, B., Habbema, J. and de Vlas, S. (2006) Mobility and HIV in tanzanian couples: Both mobile persons and their partners show increased risk. AIDS, 20, 601-608. doi:10.1097/01.aids.0000210615.83330.b2

[6] Vissers, D., Voeten, H., Urassa, M., Isingo, R., Ndege, M., Kumogola, Y., Mwaluko, G., Zaba, B., de Vlas, S. and Habbema, J. (2008) Separation of spouses due to travel and living apart raises HIV risk in Tanzanian couples. Sexually Transmitted Diseases, 35, 714-720. doi:10.1097/OLQ.0b013e3181723d93

[7] Stansbury, J.P. and Sierra, M. (2004) Risks, stigma and Honduran Garífuna conceptions of HIV/AIDS. Social Science \& Medicine, 59, 457-471. doi:10.1016/j.socscimed.2003.11.013

[8] Kerns, V. (1992) Female control of sexuality: Garífuna women at middle age. In: Kerns, V. and Brown, J., Eds., In Her Prime: New Views of Middle-Aged Women, University of Illinois Press, Champaign, 95-112.

[9] PAHO (2001) HIV and AIDS in the Americas: An epidemic with many faces.

http://www.paho.org/English/HCP/HCA/faces final.pdf

[10] Garcıa, J.M., Salavarrıa, N., Valentın, D., Ramirez, D. and Sierra, M. (2000) Proyecto "educación preventiva y fortalecimiento de la respuesta local en las comunidades garífunas." Aspectos Sociodemográficos, Conocimientos, Creencias, Actitudes y Prácticas Relacionadas con la Transmisión de ITS/VIH en las Comunidades Garífunas. Tegucigalpa, Honduras. MDC: Asociación El Buen Pastor; Organización Panamericana de la Salúd/ONUSIDA, Departamentos de ETS/SIDA/TB, Secretaria de Salúd.

[11] UNAIDS (2010) Honduras: HIV/AIDS health profile. http://www.usaid.gov/our_work/global_health/aids/Count ries/lac/honduras.pdf 
[12] Adimora, A.A., Schoenbach, V.J. and Bonas, D.M. (2002) Concurrent sexual partnerships among women in the United States. Epidemiology, 13, 320-327. doi:10.1097/00001648-200205000-00013

[13] Morris, M. (2008) The relationship between concurrent partnerships and HIV transmission. Presentation to the PEPFAR General Population and Youth HIV Prevention, Technical Working Group and AIDSTAR-One Project, 29-30 October, Washington, DC.

[14] Castor, D., Jolly, P. and Furlonge, C. (2002) Determinants of gonorrhea infection among STI clinic attenders in Trinidad-II: Sexual behavioral factors. International Journal of STD/AIDS, 13, 46-51. doi:10.1258/0956462021924479

[15] Potterat, J., Zimmerman-Rogers, H. and Muth, S. (1999) Chlamydia transmission: Concurrency, reproduction number, and the epidemic trajectory. American Journal of Epidemiology, 150, 1331-1339. doi:10.1093/oxfordjournals.aje.a009965

[16] Rosenberg, G.J., Gurvey, J.E. and Adler, N. (1999) Concurrent sex partners and risk for sexually transmitted diseases among adolescents. Sexually Transmitted Diseases, 26, 208-212. doi:10.1097/00007435-199904000-00004

[17] Drumright, L.N., Gorbach, P.M. and Holmes, K.K. (2004) Do people really know their sex partners? Concurrency, knowledge of partner behavior, and sexually transmitted infections within partnerships. Sexually Transmitted Diseases, 31, 437-442. doi:10.1097/01.OLQ.0000129949.30114.37

[18] Rothschild, M. (1999) Carrots, sticks, and promises: A conceptual framework for the management of public health and social issue behaviors. Journal of Marketing, 63, 24-37. doi: $10.2307 / 1251972$

[19] Rosenstock, I.M. (1974) Historical origins of the health belief model. Health Education Monographs, 2, 328-335.

[20] Fishbein, M. and Azjen, I. (1975) Belief, attitude, intention, and behavior. Addison-Wesley, Boston.

[21] Chapman, S. (2004) Evaluating social marketing interventions. In: Thorogood, M. and Coombes, Y., Eds., Evaluating Health Promotion, Oxford University Press, Oxford, 93-110. doi:10.1093/acprof:oso/9780198528807.003.0007

[22] Scott-Wright, A., Hakre, S., Bryan, J.P., Jaramillo, R., Reyes, L.G., Cruess, D., Macarthy, P.O. and Gaydos, J.C. (1997) Hepatitis B virus, human immunodeficiency virus type-1, and syphilis among women attending prenatal clinics in Belize, Central America. American Journal of Tropical Medicine \& Hygiene, 56, 285-290.

[23] Senn, T.E., Scott-Sheldon, L.A., Seward, D.X., Wright, E.M. and Carey, M.P. (2011) Sexual partner concurrency of urban male and female STD clinic patients: A qualitative study. Archives of Sexual Behavior, 40, 775-784. doi:10.1007/s10508-010-9688-y

[24] Joshi, A. (2010) Multiple sexual partners: Perceptions of young men in Uganda. Journal of Health Organization and Management, 24, 520-527.

[25] Mavhu, W., Langhaug, L., Pascoe, S., Dirawo, J., Hart, G. and Cowan, F. (2011) A novel tool to assess community norms and attitudes to multiple and concurrent sexual partnering in rural Zimbabwe: Participatory attitudinal ranking. AIDS Care, 23, 52-59. doi:10.1080/09540121.2010.490257

[26] Bingenheimer, J.B. (2010) Men's multiple sexual partnerships in 15 Sub-Saharan African countries: Sociodemographic patterns and implications. Studies in Family Planning, 41, 1-17. doi:10.1111/j.1728-4465.2010.00220.x 